\title{
Characterization of Isomeric Unsulfated Glycosaminoglycan Oligosaccharides by Mass Spectrometry/Mass Spectrometry
}

\author{
Toshikazu Minamisawa, ${ }^{1,2 *}$ Kiyoshi Suzuki, ${ }^{2}$ Hiroshi Maeda, ${ }^{2}$ \\ Satoshi Shimokata, ${ }^{2,3}$ Nobuo Sugiura, ${ }^{2,3}$ Koji Kimata, ${ }^{3}$ \\ and Jun HiraBAyASHI ${ }^{1}$
}

\author{
${ }^{1}$ Research Center for Glycoscience, National Institute of Advanced Industrial Science and Technology \\ (AIST), Tsukuba, IBARAKI, JAPAN \\ ${ }^{2}$ Central Research Laboratories, Seikagaku Corporation, Higashi-yamato, TOKYO, JAPAN \\ ${ }^{3}$ Institute for the Molecular Science of Medicine, Aichi Medical University, Nagakute, Aichi-gun, \\ AICHI, JAPAN
}

\begin{abstract}
Both saturated and unsaturated forms of isomeric unsulfated glycosaminoglycan (GAG) oligosaccharides, i.e., tetrasaccharides of chondroitin $(\mathrm{CH})$ and hyaluronan $(\mathrm{HA})$, were analyzed by electrospray ionization mass spectrometry/mass spectrometry. Although the only structural difference between them was the hydroxyl group at the C-4 position in $N$-acetylhexosamine (GalNAc or GlcNAc, respectively), given the same $m / z$ value of precursor ions, these isomers in both their saturated and unsaturated forms could be separated by careful examination of diagnostic fragment ions in their product ion mass spectra when the relative abundances of these fragment ions were considered. In addition, the product ion mass spectrum of the unsaturated HA tetrasaccharide was compared with its linkage isomer, $N$-acetylheparosan tetrasaccharide. In this case, the isomers were more easily differentiated by comparing their characteristic spectral patterns. By adopting this approach, systematic differentiation of isomeric unsulfated GAG oligosaccharides should be achieved by means of fragmentation. It should also contribute widely to GAG-related biochemical and medicinal research in the future.
\end{abstract}

(Received October 30, 2006; Accepted November 28, 2006)

\section{Introduction}

Glycosaminoglycans (GAGs) are biofunctional polysaccharides known to have a regularly alternating backbone consisting of hexuronic acid (HexA) and $\mathrm{N}$ acetylhexosamine (HexNAc). Some of them usually undergo post-glycosylation modifications such as sulfation and HexA epimerization to complete their mature structures. Differences in glycosidic linkages, sulfate positions, C-5 epimer of HexA, i.e., glucuronic acid (GlcA) or iduronic acid, and the type of HexNAc, i.e., $N$-acetylgalactosamine (GalNAc) or $N$-acetylglucosamine (GlcNAc), give rise to multiple isomeric structures that cannot be readily differentiated by conventional analytical techniques.

In recent decades, mass spectrometry/mass spectrometry (MS/MS) has been increasingly used to differentiate numerous kinds of carbohydrate isomer. For example, structural isomers with regard to glycosidic linkage position, ${ }^{1-8)}$ sulfated or phosphated position, ${ }^{4,9)-11)}$ anomeric configuration, 1,2$\left.), 8\right), 12$ and epimers ${ }^{10)}$,13)-15) have been successfully differentiated by MS/MS, with no or minimal derivatization of the sample. MS is thus becoming fully accepted as a tool

* Correspondence to: Toshikazu Minamisawa, Central Research Laboratories, Seikagaku Corporation, 3-1253 Tateno, Higashi-yamato, Tokyo 207-0021, JAPAN, e-mail: toshikazu.minamisawa@seikagaku.co.jp for structural analysis of carbohydrates. For sulfated GAGs, their unsaturated disaccharides, including sulfated position isomers, have been differentiated by multiple-stage MS $\left(\mathrm{MS}^{\mathrm{n}}\right)$ to establish a technique for quantitative disaccharide composition analysis. ${ }^{16)-20)}$ Longer isomeric oligosaccharides with regard to sulfated positions have also been discriminated by examining the relative abundances of their fragment ions in MS/MS. ${ }^{21)}$ Surprisingly, the analysis of unsulfated GAG isomers has not yet been described systematically.

We recently prepared a series of $\mathrm{N}$-acetylheparosan (NAH) oligosaccharides, one of the unsulfated GAGs, and characterized them by MS/MS. ${ }^{22), 23)}$ The fragmentation behavior observed was unique, reflecting the alternating HexA-HexNAc sequence, as well as the glycosidic linkage position. ${ }^{23)}$ This prompted us to confirm MS potentiality to differentiate structural isomers of NAH oligosaccharides.

The present study compared the electrospray ionization (ESI) product ion mass spectra of isomeric unsulfated GAG oligosaccharides, especially the tetrasaccharides of chondroitin $(\mathrm{CH})$, hyaluronan (HA), and $\mathrm{NAH} . \quad \mathrm{CH}$ and $\mathrm{HA}$ are isomers in the C-4 hydroxyl configuration of HexNAc (C-4 epimers), whereas HA and NAH are isomers in the glycosidic linkages. Their structures are given as follows.

CH: $\quad-4 \mathrm{GlcA} \beta 1-3 \mathrm{GalNAc} \beta 1-$ 


\section{HA: $\quad-4 \mathrm{GlcA} \beta 1-3 \mathrm{GlcNAc} \beta 1-$}

\section{NAH: -4 GlcA $\beta 1-4$ GlcNAc $\alpha 1-$}

The oligosaccharide structures of these unsulfated GAGs have been conventionally determined by nuclear magnetic resonance (NMR) or exhaustive enzymatic digestion followed by analysis using a high-performance liquid chromatography. In fact, NMR is the most reliable choice in analytical carbohydrate chemistry, whereas use of GAG-backbone-specific enzymes is a well-established method of investigating GAG structures. However, each has intrinsic disadvantages such as being time-consuming. Thus, our challenge here was to utilize MS to offer an alternative technique for identifying GAG oligosaccharides, focusing on unsulfated ones. This is the first description of a comparative characterization of isomeric unsulfated GAG oligosaccharides by MS/MS.

\section{Experimental}

\subsection{Oligosaccharides}

Both saturated $\mathrm{CH}$ and $\mathrm{HA}$ tetrasaccharides were prepared according to the method reported previous$\left.1 y,{ }^{24)}, 25\right)$ with minimal modification. Briefly, both $\mathrm{CH}$ and HA (Seikagaku Corporation, Japan) were digested with a testicular hyaluronidase (Type-V, Sigma, USA). The resulting oligosaccharides were separated by anion-exchange chromatography followed by desalting by size-exclusion chromatography, to obtain saturated tetrasaccharides (CH4, HA4).

Unsaturated $\mathrm{CH}$ and $\mathrm{HA}$ tetrasaccharides were prepared by partial depolymerization of $\mathrm{CH}$ and HA with a bacterial hyaluronidase (Streptomyces hyalurolyticus, Sigma) and a chondroitinase ABC (Seikagaku Corporation), respectively, and subsequent size-exclusion chromatography produced unsaturated $\mathrm{CH}$ and $\mathrm{HA}$ tetrasaccharides $(\triangle \mathrm{CH} 4, \Delta \mathrm{HA} 4)$.

\subsection{ESI-MS and MS/MS}

Negative ion mode ESI-MS or ESI-MS/MS was performed using a Bruker Daltonik GmbH (Bremen, Germany) Esquire 3,000 Plus instrument equipped with an ion trap analyzer. Oligosaccharides were dissolved ( $c a$. $10 \mathrm{pmol} / \mu \mathrm{L}$ ) in 50\% methanol (spectrophotometric grade, Aldrich Chemical Co., USA) containing $2.5 \mathrm{mM}$ ammonium acetate, $\mathrm{pH}$ 6.0, and infused into the mass spectrometer directly using a syringe pump at a flow rate of $360 \mu \mathrm{L} / \mathrm{h}$. The instrument was operated at a capillary voltage of $-3.8 \mathrm{kV}$ and an end plate offset of $-500 \mathrm{~V}$. Dry nitrogen gas flow was $4.0 \mathrm{~L} / \mathrm{min}$, and the drying temperature was set at $300^{\circ} \mathrm{C}$. For collisioninduced dissociation (CID) in MS/MS, the particular ion of interest was isolated using an isolation width of 1 $m / z$ value and excited for $40 \mathrm{~ms}$. The fragmentation amplitude was adjusted to $1.0 \mathrm{~V}$. For each experiment, the mass range scanned was $m / z 50$ to 1,500 or 2,000 , and the scan resolution was set at $5,500 \mathrm{~m} / z / \mathrm{s}$.

\section{Results and Discussion}

This study deals with both saturated and unsaturated forms of GAG tetrasaccharides with a saturated glucuronic acid (GlcA) and an unsaturated uronic acid (gluco-4-enopyranosyluronic acid, $\Delta \mathrm{UA}$ ) at the nonreducing end (Table 1). As is well known, the appearance of HexA (saturated or unsaturated) at the nonreducing end depends on the type of GAG-degrading enzyme used. ${ }^{26)}$ Using MS, a pair of saturated and unsaturated oligosaccharides with identical chain length (which are not isomers) can be easily discriminated since there is an $18 \mathrm{u}$ difference, corresponding to one $\mathrm{H}_{2} \mathrm{O}$ molecule, between them. However, a pair of isomers, either saturated or unsaturated, gives the same $m / z$ value in the mass spectra; therefore, they cannot be separated at this stage. We describe below our attempt to differentiate them by MS/MS.

\subsection{Saturated tetrasaccharides}

Saturated tetrasaccharides of both $\mathrm{CH}$ and $\mathrm{HA}(\mathrm{CH} 4$ and HA4) were analyzed by ESI-MS/MS. As reported in several articles, ESI-MS of HA4 under typical conditions gives rise to both singly and doubly deoprotonated molecules. ${ }^{24), 27)}$ These results were reproducible under the conditions used in this study. Thus, the fragmentation of each of the precursor ions in CID was examined.

Figure 1 compares the negative ion ESI product ion mass spectra of $\mathrm{CH} 4$ (A) and HA4 (B), when their doubly deprotonated molecules $(m / z 387)$ were fragmented. Each gave a doubly charged $\mathrm{C}_{3}$ ion (by the nomenclature system according to the literature ${ }^{28)}$ ) at $m / z 285.5$ most intensely, accompanying a singly charged $\mathrm{C}_{3}$ ion at $m / z 572$ in lower abundance. Assuming that the nascent charges were located on the carboxyl groups in the precursor ion, the production of the singly charged $\mathrm{C}_{3}$ ion in MS/MS suggested that one of the negative charges had migrated to the reducing end HexNAc, i.e., the $Z_{1}$ moiety, during the fragmentation process. It is noteworthy that the abundance of the singly charged $\mathrm{C}_{3}$ ion relative to the doubly charged one (base peak) was approximately 2.0-fold higher in CH4 than HA4 (Figs. 1A and B, Table 2). The difference was speculated to be associated with the marked production of the $\left[\mathrm{Z}_{1}-\mathrm{OCHCH}_{2} \mathrm{OH}\right]^{-}$ion at $\mathrm{m} / \mathrm{z}$ 142 in $\mathrm{CH} 4$ (less abundant in HA4). These observations, suggesting easier susceptibility of the $\mathrm{C}_{3}-Z_{1}$ cleavage and the charge migration in $\mathrm{CH} 4$, could be explained by the following three reasons: first, a mo-

Table 1. Oligosaccharides Examined in This Study

\begin{tabular}{ccc}
\hline UA at non-reducing end & Abbreviation & Oligosaccharide sequence \\
\hline \multirow{2}{*}{ Saturated } & $\mathrm{CH} 4$ & GlcA $\beta 1-3 \mathrm{GalNAc} \beta 1-4 \mathrm{GlcA} \beta 1-3 \mathrm{GalNAc}$ \\
& $\mathrm{HA} 4$ & GlcA $\beta 1-3 \mathrm{GlcNAc} \beta 1-4 \mathrm{GlcA} \beta 1-3 \mathrm{GlcNAc}$ \\
\hline \multirow{2}{*}{ Unsaturated } & $\Delta \mathrm{CH} 4$ & $\Delta \mathrm{UA} \beta 1-3 \mathrm{GalNAc} \beta 1-4 \mathrm{GlcA} \beta 1-3 \mathrm{GalNAc}$ \\
& $\Delta \mathrm{HA} 4$ & $\Delta \mathrm{UA} \beta 1-3 \mathrm{GlcNAc} \beta 1-4 \mathrm{GlcA} \beta 1-3 \mathrm{GlcNAc}$ \\
& $\Delta \mathrm{NAH} 4$ & $\Delta \mathrm{UA} \beta 1-4 \mathrm{GlcNAc} \alpha 1-4 \mathrm{GlcA} \beta 1-4 \mathrm{GlcNAc}$ \\
\hline
\end{tabular}




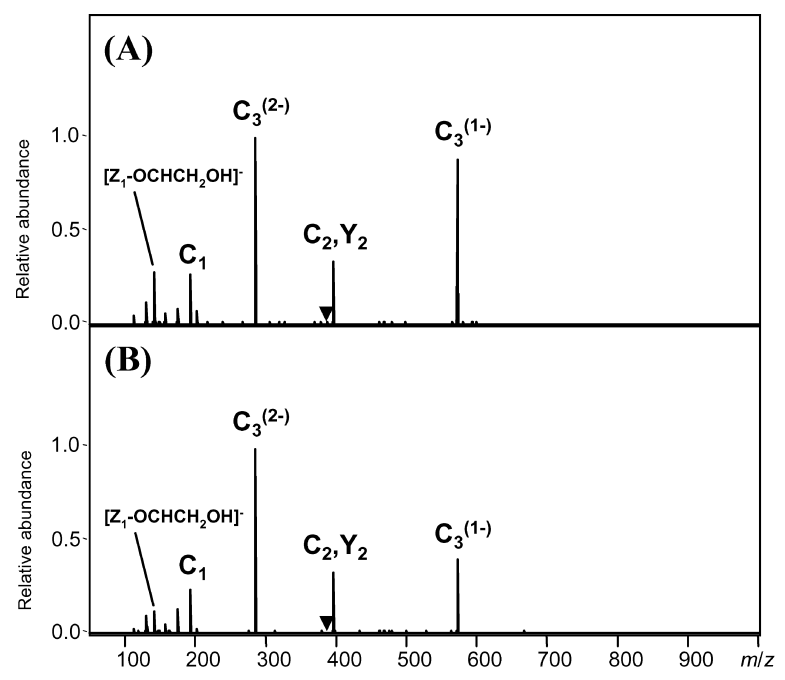

(C)

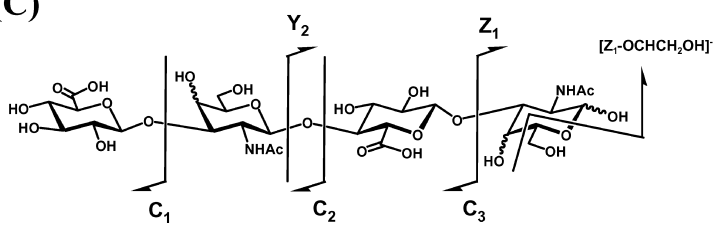

(D)

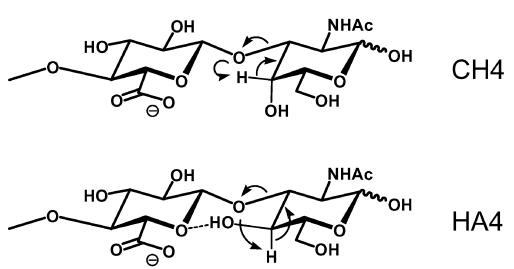

$\int C_{3}-Z_{1}$ cleavage with a charge migration

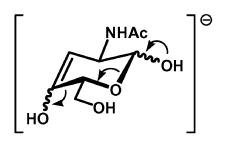

$\sqrt{\downarrow} \rightleftharpoons \underset{\mathrm{OH}}{\mathrm{O}}$<smiles>C/C=C\C(=O)O</smiles>

Fig. 1. Comparison of fragmentations of $\mathrm{CH} 4$ (A) and HA4 in ESI-MS/MS (B). The double-charge deprotonated molecules $(\mathrm{m} / z$ 387) were chosen as precursor ions (closed reverse triangles). Scheme (C) summarizes the assigned cleavages. (D) The plausible schema for generating a $\left[Z_{1}-\mathrm{OCHCH}_{2} \mathrm{OH}\right]^{-}$ion. The $\mathrm{C}_{3}-\mathrm{Z}_{1}$ cleavage takes place under the elucidated mechanism, ${ }^{18)}$ and the negative charge, located at the carboxyl group in the neighboring GlcA initially, migrates to the reducing end HexNAc simultaneously. The resulting $Z_{1}$ ion is stabilized by ready release of the $\left[\mathrm{OCHCH}_{2} \mathrm{OH}\right]$ moiety, giving the $\left[\mathrm{Z}_{1}-\mathrm{OCHCH}_{2} \mathrm{OH}\right]^{-}$ion.

Table 2. Summary of the ESI-MS/MS Fragmentations of CH4 and HA4 $(\mathrm{m} / \mathrm{z}$ Values, Assignments, and Relative Abundances), When the Double-Charge Deprotonated Molecules ( $m / z$ 387) Were Chosen as Precursor Ions The values represent the mean $\pm \mathrm{SD}$ in three experiments. Fragment ions with relative abundances below 0.05 were excluded.

\begin{tabular}{cccccc}
\hline & \multicolumn{5}{c}{ Fragment ions $(m / z$, assignment $)$} \\
\cline { 2 - 6 } Oligosaccharide & 142 & 193 & 285.5 & 396 & 572 \\
& {$\left[\mathrm{Z}_{1}-\mathrm{OCHCH} \mathrm{CH}_{2}\right]^{-}$} & $\mathrm{C}_{1}$ & $\mathrm{C}_{3}{ }^{(2-)}$ & $\mathrm{C}_{2}, \mathrm{Y}_{2}$ & $\mathrm{C}_{3}{ }^{(1-)}$ \\
\hline $\mathrm{CH} 4$ & $0.25 \pm 0.04$ & $0.25 \pm 0.02$ & 1.00 & $0.31 \pm 0.04$ & $0.77 \pm 0.10$ \\
$\mathrm{HA} 4$ & $0.08 \pm 0.01$ & $0.25 \pm 0.04$ & 1.00 & $0.34 \pm 0.02$ & $0.39 \pm 0.09$ \\
\hline
\end{tabular}

lecular dynamics study described that the C-4 hydroxyl of the GlcNAc in HA4 formed a stable intramolecular hydrogen bond with the ring oxygen in the GlcA, stabilizing the GlcA $\beta 1-3 \mathrm{GlcNAc}$ linkage (Fig. 1D). ${ }^{29)}$ Such stabilization would be weakened in $\mathrm{CH} 4$, of which C-4 hydroxyl was in the axial configuration. Second, the cleavage, based on the elucidated mechanism, ${ }^{18)}$ could presumably proceed more readily in $\mathrm{CH} 4$, since the equatorial-to-equatorial orientation between the glycosidic oxygen and the C- 4 hydrogen of the GalNAc would be advantageous for the cleavage. Third, a comparable study on the potentials of mean force for the glycosidic torsion angles suggested that the GlcA $\beta 1-3$ HexNAc linkage of $\mathrm{CH}$ was a little more flexible than that of $\mathrm{HA},{ }^{30}$ which would make the charge more accessible to the GalNAc in $\mathrm{CH}$, resulting in more intense appearance of the singly charged $\mathrm{C}_{3}$ ion. The resulting $Z_{1}$ ion could be stabilized by a neutral loss, and is detected as a $\left[\mathrm{Z}_{1}-\mathrm{OCHCH}_{2} \mathrm{OH}\right]^{-}$ion.
The difference in the abundance of the singly charged $\mathrm{C}_{3}$ ion as well as the $\left[\mathrm{Z}_{1}-\mathrm{OCHCH}_{2} \mathrm{OH}\right]^{-}$ion, between $\mathrm{CH}$ 4 and HA4, was highly reproducible (Table 2), indicating that those isomeric tetrasaccharides were successfully differentiated.

On the other hand, the single-charge deprotonated molecules of the isomers at $m / z 775$ fragmented to produce two glycosidic cleavage ions at $\mathrm{m} / z 396$ (assigned as both $\mathrm{C}_{2}$ and $\left.\mathrm{Y}_{2}\right)$ and $m / z 572\left(\mathrm{C}_{3}\right)$, the last of which represented the base peak signal (Figs. 2A and B). This spectral pattern was highly similar to the previously reported one for HA tetrasaccharide. ${ }^{31)}$ In the spectra, a fragment ion with $\mathrm{m} / \mathrm{z}$ below the low mass cut-off value (in this case, $c a . m / z 215$ ) can, in principle, never be observed. However, a small but reproducible difference in the relative abundance of the $m / z 396$ ions was found between $\mathrm{CH} 4$ and HA4 in this study ( $c a$. 1.6-fold higher in HA4 than $\mathrm{CH} 4$, the values are not shown). This could be due to the differ- 


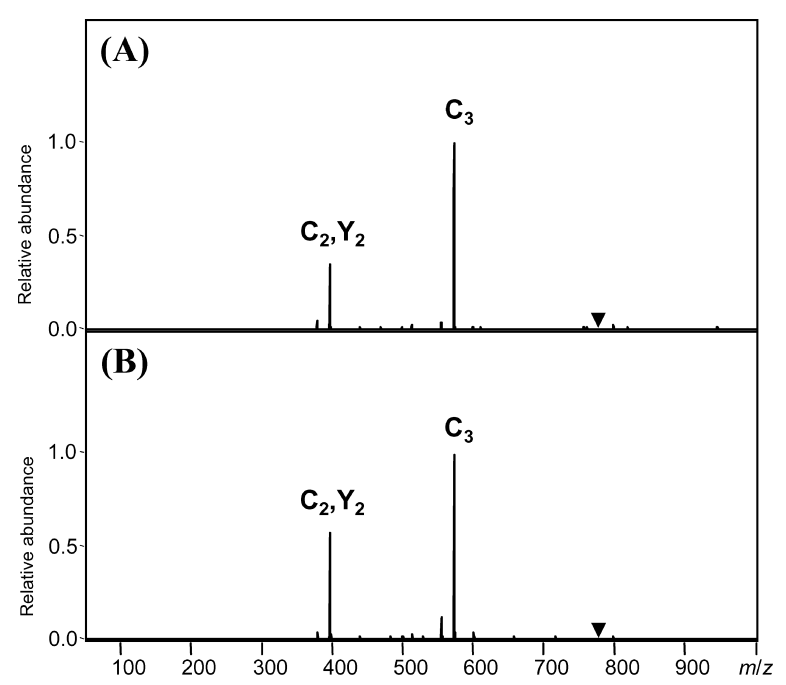

Fig. 2. ESI product ion mass spectra of $\mathrm{CH} 4$ (A) and HA4 (B) when the single-charge deprotonated molecules $(\mathrm{m} / \mathrm{z}$ 775) were chosen as precursor ions.

ent fragmentation susceptibility between the glycosides of GalNAc (CH4) and GlcNAc (HA4), by which the isomer differentiation was made possible.

\subsection{Unsaturated tetrasaccharides}

Similarly, the product ion mass spectra of the isomeric unsaturated tetrasaccharides $(\Delta \mathrm{CH} 4$ and $\Delta \mathrm{HA} 4)$ were acquired by fragmentation of their singly deprotonated precursor ions at $m / z 757$. Figure 3 and Table 3 show the results including that for NAH tetrasaccharide $(\Delta \mathrm{NAH} 4) .{ }^{23)}$ As in the case of saturated forms, $\mathrm{C}_{3}$ ions $(m / z 554)$ were produced for $\Delta \mathrm{CH} 4$ and $\Delta \mathrm{HA} 4$ most intensely. This demonstrated that this glycosidic linkage had been most fragile in the structure of the series. The other fragment ion observed in MS/MS was in low abundance but different for the isomers, that is, $Z_{3}(m / z 581)$ and $Y_{2}(m / z 396)$ ions were produced for $\Delta \mathrm{CH} 4$ and $\Delta \mathrm{HA} 4$, respectively (Figs. $3 \mathrm{~A}, \mathrm{~B}, \mathrm{D}$, E), which enabled their differentiation.

Although the structural difference remained between the $\mathrm{C}_{3}$ ions of $\triangle \mathrm{CH} 4$ and $\Delta \mathrm{HA} 4$, their $\mathrm{MS}^{3}$ commonly gave only a single signal corresponding to the released GlcA, failing to differentiate their isomerism. The specific $Z_{3}$ ion production in $\Delta \mathrm{CH} 4$ was unexplained, although the ion also appeared in the matrixassisted laser desorption/ionization-time of flight (TOF)/TOF product ion mass spectrum of $\Delta \mathrm{CH} 4$ (not shown). On the other hand, the slight appearance of the $\mathrm{Y}_{2}$ ion in $\triangle \mathrm{HA} 4$ might be consistent with the dominant cleavage of HexNAc glycoside in the fragmentation of HA4 (rather than $\mathrm{CH} 4$, described above). It should be noted that a disaccharide-type fragment ion, observed for saturated versions in significant abundance $\left(\mathrm{C}_{2}, \mathrm{Y}_{2}\right)$, appeared in much smaller amounts for unsaturated ones $\left(\mathrm{Y}_{2}\right)$. This demonstrated that a HexA structure at the non-reducing end, i.e., in saturated or unsaturated form, significantly influenced the fragmentation susceptibility of a glycosidic linkage distant from the non-reducing end, giving a particular fragmentation pattern.

Next, the result of $\triangle \mathrm{HA} 4$ in MS/MS was compared with that of $\triangle \mathrm{NAH} 4$, which was isomeric in the glycosidic linkage (Table 1). As shown in Fig. $3 \mathrm{C}, \triangle \mathrm{NAH} 4$ also fragmented to give $\mathrm{C}_{3}$ ion with the highest abundance, whereas no other fragment ion appeared at any $m / z$ identical to that of $\Delta \mathrm{HA} 4$ fragment ions. Unique ions for $\Delta \mathrm{NAH} 4$ were observed at $m / z 739\left(\left[\mathrm{M}-\mathrm{H}_{2} \mathrm{O}\right]^{-}\right)$,
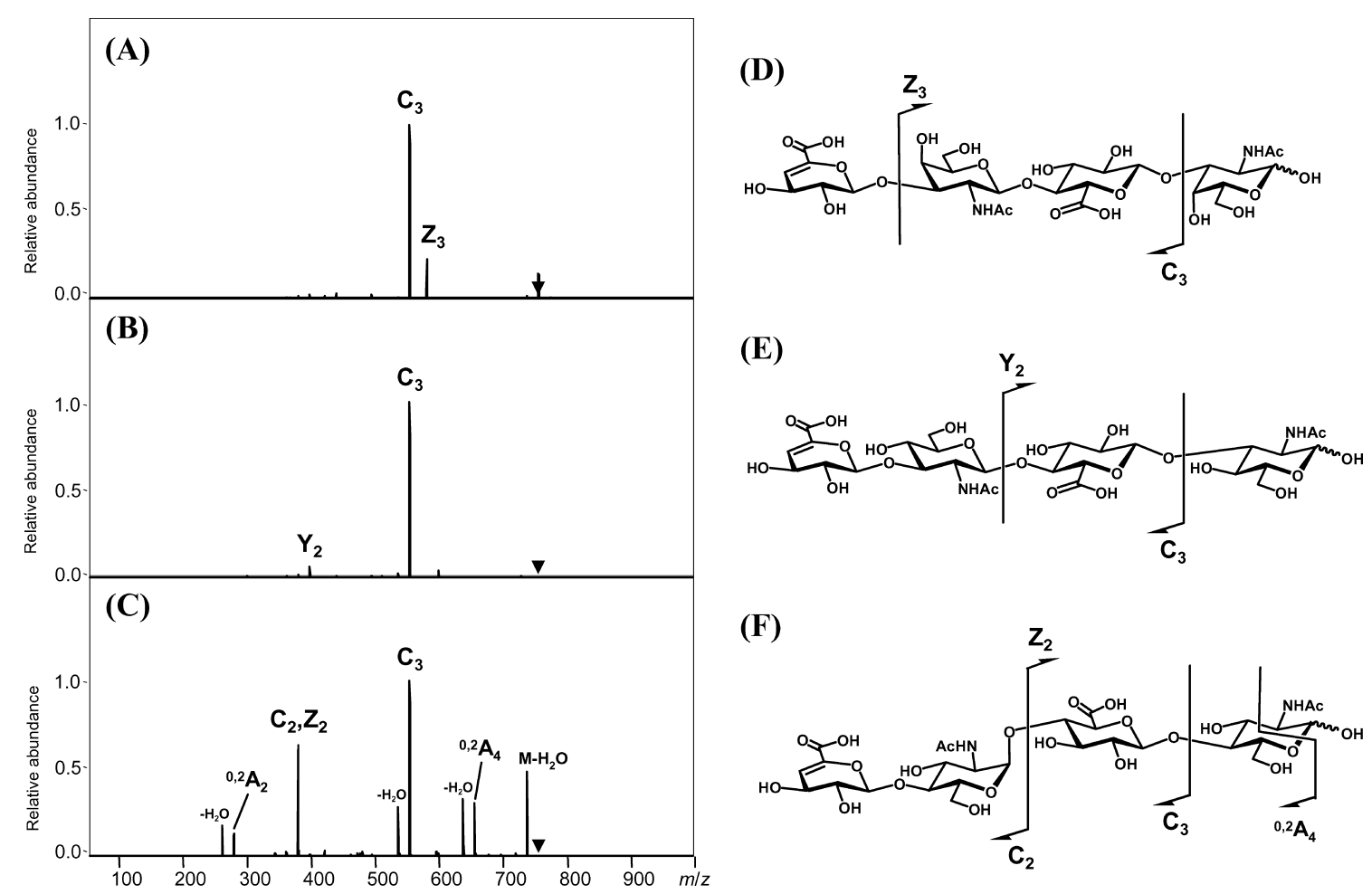

Fig. 3. Comparison of the ESI-product ion mass spectra of $\Delta \mathrm{CH} 4$ (A), $\Delta \mathrm{HA} 4$ (B), and $\Delta \mathrm{NAH} 4$ (C). The single-charge deprotonated molecules $(\mathrm{m} / \mathrm{z}$ 757) were chosen as precursor ions. Each of the fragmentations is also shown as a scheme (D, E, F). 
Table 3. Summary of the ESI-MS/MS Fragmentations of $\Delta \mathrm{CH} 4, \Delta \mathrm{HA} 4$, and $\triangle \mathrm{NAH} 4$, When the Single-Charge Deprotonated Molecules $(m / z$ 757) Were Chosen as Precursor Ions

The mean values in the two experiments are presented.

\begin{tabular}{ccccccccc}
\hline & \multicolumn{7}{c}{ Fragment ions $(m / z$, assignment $)$} \\
\cline { 2 - 8 } Oligosaccharide & 277 & 378 & 396 & 554 & 581 & 656 & 739 \\
& $\mathrm{Z}_{2}{ }^{0.2} \mathrm{~A}_{4}$ & $\mathrm{C}_{2}, \mathrm{Z}_{2}$ & $\mathrm{Y}_{2}$ & $\mathrm{C}_{3}$ & $\mathrm{Z}_{3}$ & ${ }^{2} \mathrm{~A}_{4}$ & {$\left[\mathrm{M}-\mathrm{H}_{2} \mathrm{O}\right]^{-}$} \\
\hline$\Delta$ CH4 & - & - & - & 1.00 & 0.23 & - & - \\
$\Delta$ HA4 & - & - & 0.07 & 1.00 & - & - & - \\
$\Delta$ NAH4 & 0.13 & 0.63 & - & 1.00 & - & 0.30 & 0.48 \\
\hline
\end{tabular}

一: not detected

$m / z 656\left({ }^{0.2} \mathrm{~A}_{4}\right)$, and $m / z 378\left(\mathrm{C}_{2}\right.$ and $\mathrm{Z}_{2}$, Figs. $\left.3 \mathrm{C}, \mathrm{F}\right)$. As reported previously, ${ }^{0.2} \mathrm{~A}$-type cross-ring cleavage at the reducing end and dehydration are common features in ESI-MS/MS fragmentation of NAH oligosaccharides. $^{23)}$ The generation of a ${ }^{0.2} \mathrm{~A}$-type ion rules out the possibility that the glycosidic linkage linked to the reducing end HexNAc is in the C-3 position. ${ }^{18)}$ Thus, this observation provided a clue for differentiating $\triangle \mathrm{DHA}$ and $\triangle \mathrm{NAH}$ oligosaccharides. It is of importance that the characteristic ion at $m / z 378\left(\mathrm{C}_{2}\right.$ and $\left.\mathrm{Z}_{2}\right)$ appears indicative of the $\alpha$-glycoside in $\Delta \mathrm{NAH} 4$, since such an ion is never observed for $\beta$-glycosides $(\Delta \mathrm{CH} 4$ and $\Delta$ HA4). This is likely to be consistent with the other study results, concluding that an $\alpha 1-4$ linkage is cleaved more readily than a $\beta 1-4$ linkage. ${ }^{32,33)}$

\section{Conclusions}

The present study is the first to demonstrate that isomeric unsulfated GAG tetrasaccharides, both saturated and unsaturated, can be differentiated by ESI-MS/MS. It can be estimated that oligosaccharides with both $\mathrm{CH}$ and $\mathrm{HA}$ backbones (i.e., C-4 hydroxyl configuration isomers) were separated by investigation of the product ion mass spectral pattern or fragment ion abundance, whereas the HA oligosaccharides were easily discriminated from NAH oligosaccharides (i.e., glycosidic linkage isomers) by searching for diagnostic ions. The latter outcome was clearly understood by the established fragmentation mechanism to form a ${ }^{0.2} \mathrm{~A}$ fragment ion ${ }^{18)}$ in the NAH backbone. In contrast, structural differences between the configuration isomers ( $\mathrm{CH}$ and $\mathrm{HA}$ ) were small; therefore, their fragmentation mechanisms were assumed to be fundamentally identical. Meanwhile, as pointed out, the C-4 hydroxyl configuration in HexNAc was likely to affect the fragmentation by the formation of inherent hydrogen bonds, resulting in different relative abundances of a relevant fragment ion. Based on the information provided here, longer isomers should be identified in a similar way; a verification study is in progress.

GAG tetrasaccharides, the focus of the present study, are in some cases obtained as end products of enzymatic digestion of parent GAGs. Since some GAGdegrading enzymes depolymerize both $\mathrm{CH}$ and $\mathrm{HA}$ chains, ${ }^{26)}$ an analytical method for differentiating those isomeric structures, as developed in this study, is required for characterizing those kinds of oligosaccharide preparation. In fact, some isomer-diagnostic ions found in the present study are of low abundance or based on a small difference, which seems insufficient for practical isomer characterization when given within the complex mixture. Therefore, the limits of the application should be investigated in detail. On the other hand, there is growing interest in the physiological functions of these unsulfated GAG oligosaccharides, ${ }^{34-37)}$ and their development as a medicinal resource is highly promising. Thus, the technique presented here should be extended for wider purposes in biochemical and medicinal research.

\section{Acknowledgements}

The authors thank Ko Hayama of the National Institute of Advanced Industrial Science and Technology (AIST) and Takatoshi Kubo of Seikagaku Corporation for their advice regarding MS. We are also grateful to Yoko Ohashi of the University of Electro-Communications for fruitful suggestions.

This work was supported in part by Japan's New Energy and Industrial Technology Development Organization (NEDO).

\section{References}

1) D. Garozzo, G. Impallomeni, E. Spina, B. N. Green, and T. Hutton, Carbohydr. Res., 221, 253 (1991).

2) B. Mulroney, J. C. Traeger, and B. A. Stone, J. Mass Spectrom., 30, 1277 (1995).

3) T. Yamagaki and H. Nakanishi, Glycoconj. J., 16, 385 (1999).

4) K. A. Thomsson, H. Karlsson, and G. C. Hansson, Anal. Chem., 72, 4543 (2000).

5) W. Chai, V. Piskarev, and A. M. Lawson, Anal. Chem., 73, 651 (2001).

6) A. Pfenninger, M. Karas, B. Finke, and B. Stahl, J. Am. Soc. Mass Spectrom., 13, 1331 (2002).

7) A. Pfenninger, M. Karas, B. Finke, and B. Stahl, J. Am. Soc. Mass Spectrom., 13, 1341 (2002).

8) J. Xue, L. Song, S. D. Khaja, R. D. Locke, C. M. West, R. A. Laine, and K. L. Matta, Rapid Commun. Mass Spectrom., 18, 1947 (2004).

9) F.-F. Hsu, J. Turk, and M. L. Gross, J. Mass Spectrom., 38, 447 (2003).

10) T. Minamisawa and J. Hirabayashi, Rapid Commun. Mass Spectrom., 19, 1788 (2005).

11) B. Tissot, J.-Y. Salpin, M. Martinez, M.-P. Gaigeot, and R. Daniel, Carbohydr. Res., 341, 598 (2006).

12) T. Yamagaki, K. Fukui, and K. Tachibana, Anal. Chem., 78, 1015 (2006).

13) H. Desaire and J. A. Leary, Anal. Chem., 71, 1997 (1999).

14) H. Desaire and J. A. Leary, Anal. Chem., 71, 4142 (1999).

15) Y. Ohashi, Y. Itoh, M. Kubota, K. Hamada, M. Ohashi, T. Hirano, and H. Niwa, Eur. J. Mass Spectrom., 10, 269 (2004). 
16) H. Desaire and J. A. Leary, J. Am. Soc. Mass Spectrom., 11, 916 (2000).

17) O. M. Saad and J. A. Leary, Anal. Chem., 75, 2985 (2003).

18) O. M. Saad and J. A. Leary, J. Am. Soc. Mass Spectrom., 15, 1274 (2004).

19) O. M. Saad, H. Ebel, K. Uchimura, S. D. Rosen, C. R. Bertozzi, and J. A. Leary, Glycobiology, 15, 818 (2005).

20) J. R. Behr, Y. Matsumoto, F. M. White, and R. Sasisekharan, Rapid Commun. Mass Spectrom., 19, 2553 (2005).

21) J. Zaia, X.-Q. Li, S.-Y. Chan, and C. E. Costello, J. Am. Soc. Mass Spectrom., 14, 1270 (2003).

22) T. Minamisawa, K. Suzuki, N. Kajimoto, M. Iida, H. Maeda, and J. Hirabayashi, Carbohydr. Res., 341, 230 (2006).

23) T. Minamisawa, K. Suzuki, and J. Hirabayashi, Rapid Commun. Mass Spectrom., 20, 267 (2006).

24) A. Tawada, T. Masa, Y. Oonuki, A. Watanabe, Y. Matsuzaki, and A. Asari, Glycobiology, 12, 421 (2002).

25) T. Ninomiya, N. Sugiura, A. Tawada, K. Sugimoto, H. Watanabe, and K. Kimata, J. Biol. Chem., 277, 21567 (2002).

26) S. Ernst, R. Langer, C. L. Cooney, and R. Sasisekharan, Crit. Rev. Biochem. Mol. Biol., 30, 387 (1995).

27) K. Takagaki, K. Kojima, M. Majima, T. Nakamura, I. Kato, and M. Endo, Glycoconj. J., 9, 174 (1992).
28) B. Domon and C. E. Costello, Glycoconj. J., 5, 397 (1988).

29) A. Almond, A. Brass, and J. K. Sheehan, Glycobiology, 8, 973 (1998).

30) M. Bathe, G. C. Rutledge, A. J. Grodzinsky, and B. Tidor, Biophys. J., 88, 3870 (2005).

31) N. G. Karlsson, B. L. Schulz, N. H. Packer, and J. M. Whitelock, J. Chromatogr. B, 824, 139 (2005).

32) T. Yamagaki and H. Nakanishi, Proteomics, 1, 329 (2001).

33) A. Kurimoto, S. Daikoku, S. Mutsuga, and O. Kanie, Anal. Chem., 78, 3461 (2006).

34) C. C. Termeer, J. Hennies, U. Voith, T. Ahrens, J. M. Weiss, P. Prehm, and J. C. Simon, J. Immunol., 165, 1863 (2000).

35) C. Termeer, F. Benedix, J. Sleeman, C. Fieber, U. Voith, K. Ahrens, K. Miyake, M. Freudenberg, C. Galanos, and J. C. Simon, J. Exp. Med., 195, 99 (2002).

36) K. L. Jobe, S. O. Odman-Ghazi, M. M. Whalen, and K. P. Vercruysse, Immunol. Lett., 89, 99 (2003).

37) H. Xu, T. Ito, A. Tawada, H. Maeda, H. Yamanokuchi, K. Isahara, K. Yoshida, Y. Uchiyama, and A. Asari, J. Biol. Chem., 277, 17308 (2002).

Keywords: Fragmentation, Glycosaminoglycan, Isomer, Oligosaccharide 